\author{
Military Technical College \\ Kobry El-Kobbah, \\ Cairo, Egypt.
}

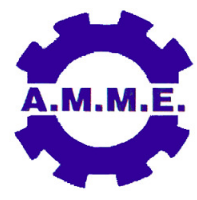

\title{
DEFORMATION MECHANISM IN NANOCRYSTALLINE MATERIALS
}

\author{
$16^{\text {th }}$ International Conference \\ on Applied Mechanics and \\ Mechanical Engineering.
}

\author{
F. A. Mohamed
}

\begin{abstract}
NANOCRYSTALLINE (nc) materials are characterized by grain sizes $<100 \mathrm{~nm}$. Because of the small grains of nc-materials, grain boundaries, junction lines, and nodes have significant volume fractions, a characteristic that can influence properties far more strongly than in conventional materials.

Nanocrystalline materials offer interesting possibilities related to many structural applications. In order to explore some of these possibilities, an understanding of the origin and nature of deformation processes in nc-materials is essential. Accordingly, the objective of this presentation is two-fold: (a) to identify the requirements that a deformation mechanism should meet in terms of accounting for the mechanical characteristics and trends that are revealed by the experimental data reported for ncmaterials; (b) to propose a deformation mechanism that not only meet these requirements but also avoid various problems associated with available deformation mechanisms.
\end{abstract}

* Professor, Department of Chemical Engineering and Material Science, Mechanical and Aerospace Engineering and Civil and Environmental Engineering, University of California, Irvine, California, 92697, USA. 